\title{
Outpatient Palliative Care in Heart Failure: Underutilized?
}

\author{
Cristina Belova $^{1 *}$, Inês Henriques ${ }^{1}$ and João Freitas ${ }^{2}$ \\ ${ }^{1}$ Family Health Unit Alcaides, ACES Alentejo Central, Portugal \\ ${ }^{2}$ Alfena Private Hospital, Portugal
}

*Corresponding author: Cristina Belova, Family Health Unit Alcaides, ACES

Alentejo Central, Portugal.

Received Date: November 12, 2020

Published Date: November 30, 2020

\begin{abstract}
Heart Failure (HF) patients have an increased burden and intricate psychosocial and decision-making needs that demand the early integration of Palliative care (PC), in order to improve the outcomes and decrease health care utilization. However, in the current era, such care occurs late in the disease course and not too often in the outpatient setting. The purpose of this review aims to understand the current state of outpatient PC in HF.

Keywords: Palliative care; Heart Failure; Outpatient
\end{abstract}

\section{Introduction}

Heart failure (HF) affects approximately 64.3 million people worldwide and its prevalence is increasing over time [1]. HF remains a progressive disease associated with high mortality rates, increased cost of care, significant symptom burden and impaired quality of life for both patients and caregivers [2-7]. A large literature calls for Palliative care (PC) for patients with HF, but there is limited experience in providing PC for these patients, especially in the outpatient/ambulatory setting [8]. The great majority of outpatient PC programs serve patients with cancer $[9,10]$, although patients with end-stage HF have been shown to have symptom burden comparable to that in cancer patients [11]. Therefore, we performed a literature review aiming to understand the current state of PC in the outpatient management of the HF patient. We searched on the online database "Pubmed" the MeSH terms "Palliative Care", "Heart Failure" and "Outpatient", and we selected 5 out of 7 papers published in the last 20 years. This research was complemented with the inclusion of other international guidelines and papers that were found relevant.

\section{Discussion}

A case series from Bekelman D, et al. [12], one of the first United States reports providing detailed characteristics in an outpatient PC program for patients with $\mathrm{HF}$, concluded that palliative $\mathrm{HF}$ care is complementary to standard HF care at all stages of the disease process. Furthermore, advocating for PC earlier in the HF trajectory may potentially reduce suffering from both physical and psychological symptoms and lessen the distress associated with this incurable condition [13]. The Evangelista L, et al. [14] study showed that implementing a PC consultation was feasible and resulted in reduced symptom burden and depression and improved quality of life in patients with symptomatic HF, supporting consensus to initiate a PC consultation earlier rather than later in the $\mathrm{HF}$ trajectory, preferably at the time of diagnosis or a hospitalization for HF exacerbation. In addition, DeGroot L, et al. [15] showed that outpatient PC decreased rehospitalizations for patients with HF.

The American College of Cardiology/American Heart Association (ACC/AHA) chronic HF guidelines first recognized the 
utility of palliative care in 2005, giving "palliation and end-of-life care" a class I recommendation [16]. The 2013 ACC/AHA chronic HF guidelines continued to recommend palliative care and, for the first time, explicitly discussed outpatient PC, adding that access to formally trained PC specialists may be limited in ambulatory settings [17].

Despite these findings and strong recommendations that patients with HF receive $\mathrm{PC}$, the referral for this type of care remains uncommon [18]. While palliative care is often available for patients hospitalized for HF, outpatient HF palliative care is rare. Unfortunately, several factors prevent outpatients with HF from receiving $\mathrm{PC}$, including physician attitudes, HF's unpredictable disease course and lack of research into PC for nononcologic patients [19]. The evidence weighs heavily in favor of developing and testing models to overcome this gap in care so that patients with HF can access PC at any stage of their illness and in any care setting [20].

\section{Conclusion}

Patients with HF have significant needs and the PC outpatient setting remains underutilized. Although PC is known to improve outcomes, HF patients rarely receive PC or its integrated late in the disease trajectory. We consider the existing literature regarding outpatient PC in HF limited and further studies are required.

\section{Acknowledgement}

None.

\section{Conflict of Interest}

No conflict of interest.

\section{References}

1. GBD 2017 Disease and Injury Incidence and Prevalence Collaborators (2018) Global, regional, and national incidence, prevalence, and years lived with disability for 354 diseases and injuries for 195 countries and territories, 1990-2017: a systematic analysis for the Global Burden of Disease Study 2017. Lancet 392: 1789-1858.

2. Curtis LH, Greiner MA, Hammill BG, Judith M Kramer, David J Whellan, et al. (2008) Early and long-term outcomes of heart failure in elderly persons, 2001-2005. JAMA Intern Med 168: 2481-2488.

3. Jong P, Vowinckel E, Liu PP, Gong Y, Tu JV (2002) Prognosis and determinants of survival in patients newly hospitalized for heart failure: a population-based study. JAMA Intern Med 162: 1689-1694.

4. van Diepen S, Tran DT, Ezekowitz JA, Gregory Schnell, Brandon M Wiley, et al. (2019) Incremental costs of high intensive care utilisation in patients hospitalised with heart failure. Eur Heart J Acute Cardiovasc Care 8(7): 660-666.
5. Bekelman DB, Havranek EP, Becker DM, Jean S Kutner, Pamela N Peterson, et al. (2007) Symptoms, depression, and quality of life in patients with heart failure. J Card Fail 13: 643-648.

6. McCarthy M, Lay M, Addington-Hall J (1996) Dying from heart disease. J R Coll Physicians Lond 30: 325-328.

7. Chung ML, Lennie TA, Mudd-Martin G, Dunbar SB, Pressler SI, et al. (2016) Depressive symptoms in patients with heart failure negatively affect family caregiver outcomes and quality of life. Eur J Cardiovasc Nurs 15: 30-38.

8. Hauptman PJ, Havranek EP (2005) Integrating palliative care into heart failure care. Arch Intern Med 165: 374-378.

9. Rabow MW, Smith AK, Braun JL, Weissman DE (2010) Outpatient palliative care practices. Arch Intern Med 170: 654- 655.

10. Meier DE, Beresford L (2008) Outpatient clinics are a new frontier for palliative care. J Palliat Med 11: 823-828.

11. Solano JP, Gomes B, Higginson IJ (2006) A Comparison of symptom prevalence in far advanced cancer, AIDS, heart disease, chronic obstructive pulmonary disease, and renal disease. J Pain Symptom Manage 31: 58-69.

12. Bekelman DB, Nowels CT, Allen LA, Shakar S, Kutner JS, et al. (2011) Outpatient palliative care for chronic heart failure: a case series. J Palliat Med 14(7): 815-821.

13. Blinderman CD, Homel P, Billings JA, Portenoy RK, Tennstedt SL (2008) Symptom distress and quality of life in patients with advanced congestive heart failure. J Pain Symptom Manage 35: 594-603.

14. Evangelista LS, Lombardo D, Malik S, Ballard-Hernandez J, Motie M, et al. (2012) Examining the effects of an outpatient palliative care consultation on symptom burden, depression, and quality of life in patients with symptomatic heart failure. J Card Fail 18(12): 894-899.

15. DeGroot L, Koirala B, Pavlovic N, Nelson K, Allen J, et al. (2020) Outpatient palliative care in heart failure: an integrative review. J Palliat Med 23: 1257-1269.

16. Hunt SA, Abraham WT, Chin MH, Arthur M Feldman, Gary S Francis, et al. (2005) ACC/AHA 2005 guideline update for the diagnosis and management of chronic heart failure in the adult. Circulation 112(12): e154-e235.

17. Yancy CW, Jessup M, Bozkurt B, Javed Butler, Donald E Casey, et al. (2013) 2013 ACCF/AHA guideline for the management of heart failure: a report of the American college of cardiology foundation/American heart association task. J Am Coll Cardiol 62(16): e147-e239.

18. Greener DT, Quill T, Amir 0, Szydlowski J, Gramling RE (2014) Palliative care referral among patients hospitalized with advanced heart failure. J Palliat Med 17(10): 1115-1120.

19. Gandesbery B, Dobbie K, Gorodeski EZ (2018) Outpatient palliative cardiology service embedded within a heart failure clinic: experiences with an emerging model of care. Am J Hosp Palliat Med 35: 635-639.

20. Chuzi S, Pak E, Desai A, Schaefer K, Warraich H (2019) Role of palliative care in the outpatient management of the chronic heart failure patient. Curr Heart Fail Rep 16: 220-228. 